\title{
Article
}

\section{Stable Field Emission from Vertically Oriented SiC Nanoarrays}

\author{
Jianfeng Xiao ${ }^{1,2}$, Jiuzhou Zhao ${ }^{2}$, Guanjiang Liu ${ }^{2}$, Mattew Thomas Cole ${ }^{3} \mathbb{D}$, Shenghan Zhou ${ }^{2,4}$, Ke Chen ${ }^{2,4}$, \\ Xinchuan $\mathrm{Liu}^{2}$, Zhenjun $\mathrm{Li}^{2,4,5, *}$, Chi $\mathrm{Li}^{2,4, *}$ and Qing Dai ${ }^{1,2,4}$
}

1 Henan Institute of Advanced Technology, Zhengzhou University, Zhengzhou 450001, China; xiaojf2020@nanoctr.cn (J.X.); daiq@nanoctr.cn (Q.D.)

2 CAS Key Laboratory of Nanophotonic Materials and Devices, CAS Key Laboratory of Standardization and Measurement for Nanotechnology, CAS Center for Excellence in Nanoscience, National Center for Nanoscience and Technology, Beijing 100190, China; zhaojz2020@nanoctr.cn (J.Z.); liugj20101120@163.com (G.L.); zhoushenghan@nanoctr.cn (S.Z.); chenke@nanoctr.cn (K.C.); liuxc2019@nanoctr.cn (X.L.)

3 Department of Electronic and Electrical Engineering, University of Bath, Bath BA2 7AY, UK; mtc47@bath.ac.uk

4 Center of Materials Science and Optoelectronics Engineering, University of Chinese Academy of Sciences, Beijing 100049, China

5 GBA Research Innovation Institute for Nanotechnology, Guangzhou 510700, China

* Correspondence: lizhenjun@nanoctr.cn (Z.L.); lichi@nanoctr.cn (C.L.)

Citation: Xiao, J.; Zhao, J.; Liu, G.; Cole, M.T.; Zhou, S.; Chen, K.; Liu, X.; Li, Z.; Li, C.; Dai, Q. Stable Field Emission from Vertically Oriented SiC Nanoarrays. Nanomaterials 2021, 11, 3025. https://doi.org/10.3390/ nano11113025

Academic Editors: Filippo Giubileo and Jun Chen

Received: 19 October 2021

Accepted: 9 November 2021

Published: 11 November 2021

Publisher's Note: MDPI stays neutral with regard to jurisdictional claims in published maps and institutional affiliations.

\begin{abstract}
Silicon carbide ( $\mathrm{SiC})$ nanostructure is a type of promising field emitter due to high breakdown field strength, high thermal conductivity, low electron affinity, and high electron mobility. However, the fabrication of the $\mathrm{SiC}$ nanotips array is difficult due to its chemical inertness. Here we report a simple, industry-familiar reactive ion etching to fabricate well-aligned, vertically orientated $\mathrm{SiC}$ nanoarrays on $4 \mathrm{H}-\mathrm{SiC}$ wafers. The as-synthesized nanoarrays had tapered base angles $>60^{\circ}$, and were vertically oriented with a high packing density $>10^{7} \mathrm{~mm}^{-2}$ and high-aspect ratios of approximately 35 . As a result of its high geometry uniformity- $5 \%$ length variation and $10 \%$ di-

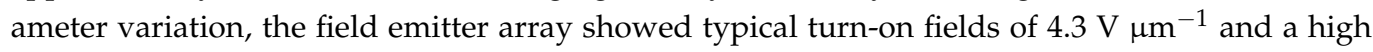
field-enhancement factor of $\sim 1260$. The $8 \mathrm{~h}$ current emission stability displayed a mean current fluctuation of $1.9 \pm 1 \%$, revealing excellent current emission stability. The as-synthesized emitters demonstrate competitive emission performance that highlights their potential in a variety of vacuum electronics applications. This study provides a new route to realizing scalable field electron emitter production.
\end{abstract}

Keywords: silicon carbide; one-dimensional nanomaterials; nanoarrays; field emission

\section{Introduction}

One-dimensional (1D) SiC nanostructures have been widely considered comparable to carbon nanotubes (CNTs) [1] as being near ideal candidates for field-emission (FE) applications given their low electron affinity, high electron mobility, and high breakdown field strength, outstanding chemical and physical stability, and high thermal conductivity [2-4]. Such chemical and physical properties make $\mathrm{SiC}$ suitable for use in high-power, high-voltage, and high-temperature, and otherwise aggressive environments [5]. Indeed, to date, the turn-on fields $\left(\mathrm{E}_{\mathrm{to}}\right.$, generally defined as the electric field to generate a current density of $10 \mu \mathrm{A} / \mathrm{cm}^{2}$ ) of $1 \mathrm{D} \mathrm{SiC}$ nanostructures is commonly several $\mathrm{V} / \mu \mathrm{m}$ [6-9], and although higher than that of CNTs, it does support the highly stable emission of very high voltage and current densities highlighting the material's potential as a novel high power FE material system [10-12].

Typical SiC 1D nanostructures, including nanowires [13], nanobelts [7], nanorods [14], and nanoneedles [15], have been realized via a variety of different fabrication methods [4,5,16], which are broadly classified, either via direct synthesis from carbon/silicon sources or via 
the processing of $\mathrm{SiC}$ substrates [8,17]. Although the $\mathrm{SiC}$ 1D nanostructures fabricated in these ways have showed excellent FE properties [8,18-20], most are produced in relatively harsh synthesis environments, often requiring very high, CMOS-incompatible processing temperatures and toxic gaseous precursors. It remains a significant engineering challenge to fabricate large-area $1 \mathrm{D} \mathrm{SiC}$ nanostructures in a cost-effective manner using simple, widely accessible laboratory equipment under nominally safe process conditions.

Dry etching is a well-established, mature technology that has been widely used in the silicone industry for more than four decades [21]. Dry etching has, as a result, become one of the central processing steps in the fabrication of many SiC nanostructures on $\mathrm{SiC}$ wafers [22-25]. In the present work, vertically oriented $\mathrm{SiC}$ nanoarrays have been successfully synthesized under controlled pressure, etching gas ratio, and etching time in a commercially available reactive ion etching system. Our field electron emission measurements suggest an $\mathrm{E}_{\text {to }}$ of the as-synthesized $\mathrm{SiC}$ nanoarrays as low as $4.3 \mathrm{~V} / \mu \mathrm{m}$, and current emission of $\sim 5 \mathrm{~mA} / \mathrm{cm}^{2}$, making them competitive with other established electron emission materials including CNT [26], Si [27], ZnO [28], and diamond [29]. Current emission stability tests demonstrated time fluctuations of $1.9 \pm 1 \%$ over $8 \mathrm{~h}$. These findings outline the potential use of the fabricated $\mathrm{SiC}$ nanoarrays in new $\mathrm{FE}$ systems that require high lifetime and high intrinsic temporal stability, such as traveling wave tubes [30], X-ray resources [31,32] and flat panel displays [5].

\section{Materials and Methods}

The vertically oriented $\mathrm{SiC}$ arrays were fabricated on commercially available $4 \mathrm{H}-\mathrm{SiC}$ substrates (TanKeBlue Semiconductor Co. Ltd, Beijing, China) via reactive ion etching (ETCHLAB 200, SENTECH Instruments GmbH, Berlin, Germany). The fabrication process is outlined in Figure 1a. In a typical process, a 4 -inch $4 \mathrm{H}$ n-type $\operatorname{SiC}((0001), 0.02 \Omega \mathrm{cm})$ single-crystal substrate was diamond scribed into $1 \times 1 \mathrm{~cm}^{2}$ samples. These were then cleaned by ultrasonication in acetone for $15 \mathrm{~min}$, followed by rinsing in isopropanol and deionized water prior to a final clean in $\mathrm{HF}$ and ethanol ( $\left.\mathrm{HF}(40 \%): \mathrm{C}_{2} \mathrm{H}_{5} \mathrm{OH}(99 \%)=1: 1\right)$ for $3 \mathrm{~min}$ to remove any surface oxides prior to RIE. RIE on the C-face (0001) was conducted at $200 \mathrm{~W}$ at $5 \mathrm{~Pa}$ under $16 \mathrm{sccm} \mathrm{SF}_{6}$ (Beijing Huanyu Jinghui Jingcheng Gas Technology Co., Ltd, Beijing, China, $99.999 \%$ ) and $4 \mathrm{sccm} \mathrm{O}_{2}(99.999 \%$, Beijing Huanyu Jinghui Jingcheng Gas Technology Co., Ltd, Beijing, China), with the chamber being ashed with $\mathrm{O}_{2}$ plasma ( $200 \mathrm{~W}, 5 \mathrm{~Pa}, 10 \mathrm{~min}$ ) prior to sample etching. After RIE, the etched wafers were immersed in $\mathrm{HF}$ and ethanol ( $\left.\mathrm{HF}(40 \%): \mathrm{C}_{2} \mathrm{H}_{5} \mathrm{OH}(99 \%)=1: 1\right)$ for $3 \mathrm{~min}$ for a second time so as to remove newly grown surface oxides. To electrically contact the produced nanoarrays, an ohmic contact was formed on the substrate backside with $\mathrm{Ni}(100 \mathrm{~nm})$ deposited by electron beam evaporation (OHMIKER-50B, Cello Technology Co., Ltd, Hsinchu, China) annealed at $950{ }^{\circ} \mathrm{C}$ at $<10 \mathrm{~Pa}$ under $100 \mathrm{sccm} \operatorname{Ar}(99.999 \%$, Chengdu Jinghao Chemical Products Co., Ltd, Chengdu, China) [33].
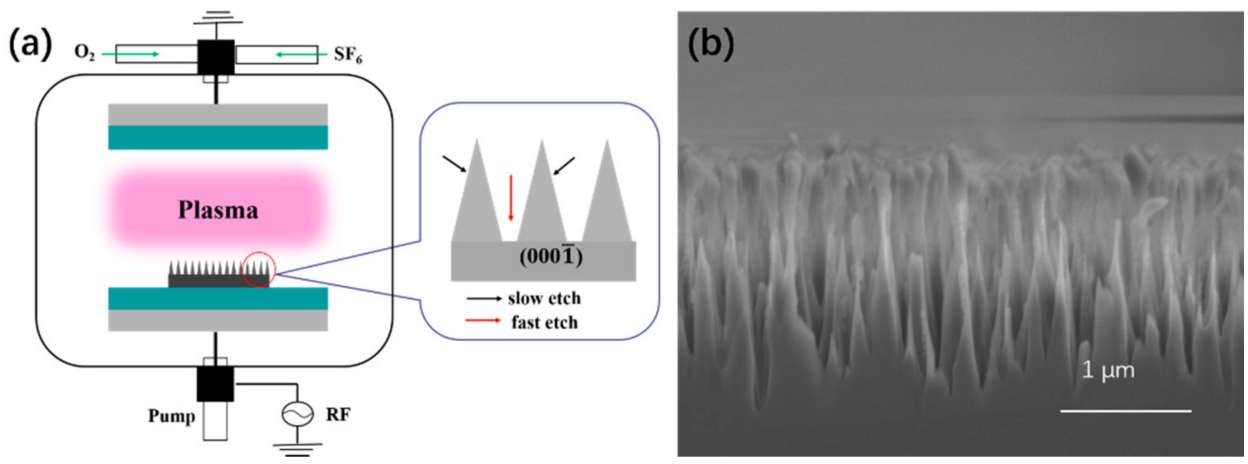

Figure 1. (a) Schematic diagram of RIE etching $4 \mathrm{H}-\mathrm{SiC}$ wafer substrate and (b) cross-section of scanning electron microscope (SEM) image after RIE etching for $20 \mathrm{~min}$. 
FE measurements, the scheme of which is shown in Figure A1, were conducted in a custom-built, continuously turbo-pumped vacuum system operating at a base pressure of $<5 \times 10^{-6} \mathrm{~Pa}$ at room temperature. The $\mathrm{SiC}$ wafer covered with $0.9 \mathrm{~cm}^{2}$ of nanoarrays was fixed on the sample table using insulating tape with the anode-cathode separation distance fixed at $300 \mu \mathrm{m}$, and the $\mathrm{SiC}$ nanoarrays were facing towards an adjacent electrode. An adjustable positive voltage $(0 \sim 10 \mathrm{kV})$ was applied to a polished steel counter anode using a power supply (DW-P103-20, Tianjin Dongwen High Voltage Power Supply Co., Ltd, Tianjin, China). A $980 \Omega$ resistor was used to measure the emission current, with a $500 \mathrm{k} \Omega$ current limiting resistor connected in series to protect the power supply. Four samples fabricated with different etching times were measured in each FE measurement.

The obtained samples were characterized by scanning electron microscopy (FESEM, Hitachi-SU8220, Hitachi, Tokyo, Japan), and an energy-dispersive X-ray spectrometer (EDS) equipped high-resolution transmission electron microscopy (HR-TEM, Tecnai G2 20 STWIN, Bionand, Málaga, Spain). The emitting surface work function (WF) was measured by ultra-violet X-ray photoelectron spectroscopy (UPS) using a He I discharge lamp $(\mathrm{h} v=21.2 \mathrm{eV})$, with the WF being extracted from the secondary electron cut-off under a sample bias of $-10 \mathrm{~V}$. The position of the Fermi level was calibrated by measuring the Fermi edge of a sputter-cleaned gold sample.

\section{Results and Discussion}

These nanoarrays were formed by RIE etching on $1 \times 1 \mathrm{~cm}^{2}$ samples, without masking, to allow samples to be mounted in the size-limited FE measurement system. The mechanism of forming such vertically-oriented large-scale $\mathrm{SiC}$ nanostructures was outlined by Liu et al [34]. Figure 1a depicts the RIE setup. Figure 1 b depicts a cross-sectional SEM image of a 20-min RIE etched sample. Due to surface energy minimization, the etch rate is notably faster on the $(000 \overline{1}) \mathrm{C}$ face (approximately $75 \mathrm{~nm} / \mathrm{min}$ ) than on other etch-active planes ( $<10 \mathrm{~nm} / \mathrm{min})$. This results in the formation of spike-like nanostructures. Figure $2 \mathrm{a}-\mathrm{d}$ show typical top-view SEM images of the as-synthesized SiC nanoarrays, fabricated by the outlined RIE etching of $4 \mathrm{H}-\mathrm{SiC}$ following $10 \mathrm{~min}, 20 \mathrm{~min}, 30 \mathrm{~min}, 60 \mathrm{~min}$ etching. The vertically oriented and high packing density cone-like $\mathrm{SiC}$ nanoarrays have a random spatial distribution with an approximate tip density of $10^{6}-10^{8} \mathrm{~mm}^{-2}$. We note that as the etching time increases the radius of the tips gradually becomes larger at a rate of $\sim 5 \mathrm{~nm} / \mathrm{s}$. Nanostructures have a vertically-oriented configuration, generally with a length of $0.75-4.35 \mu \mathrm{m}$ and a base/tip diameters of 200-1000 nm/30-300 nm (as shown in Figure A2), with their geometry being comparable to commercially incumbent emitters, highlighting their potential use as large-area field emitters.

In order to explore the effect on the nanoarray geometry as a function of the etching time, we calculated the density, the length of a single nanocone, the tip radius, and the aspect ratio (defined as the ratio of length to tip radius) and plotted them as shown in Figure 3. As the etching time increases, the density of the SiC nanoarrays reduces (Figure 3d), the length of nanostructures increases (Figure 3a), the radius of the tip increases (Figure 3b), with the aspect ratio reaching a maximum at an etch time of 20 min (Figure 3c). Etching over extended time frames (>30 min) appears to homogenize the surface, with many of the smaller/finer, yet often very FE active tips being removed, resulting in more uniform deep etches.

In order to engineer high-performance FE emission systems, it is essential to understand the chemical composition of the emitters' uppermost electron-emitting surface. In order to examine the chemical compositions of the SiC nanoarrays, EDS mapping was conducted over sample areas of up to $\sim 120 \mu^{2}$. A typical EDS spectrum and map are shown in Figure 2e. The emitting surface was found to be extremely chemically uniform. They consisted principally, as expected, of Si (50.4 at\%) and C (49.6 at\%), in a near 1:1 ratio. Very little sample oxidation was noted $(<0.1$ at $\%)$, evidencing the efficacy of the post-RIE HF oxide etch. These findings suggest that the RIE dry etching does not introduce additional chemical impurities to the $\mathrm{SiC}$ nanoarray during processing. 

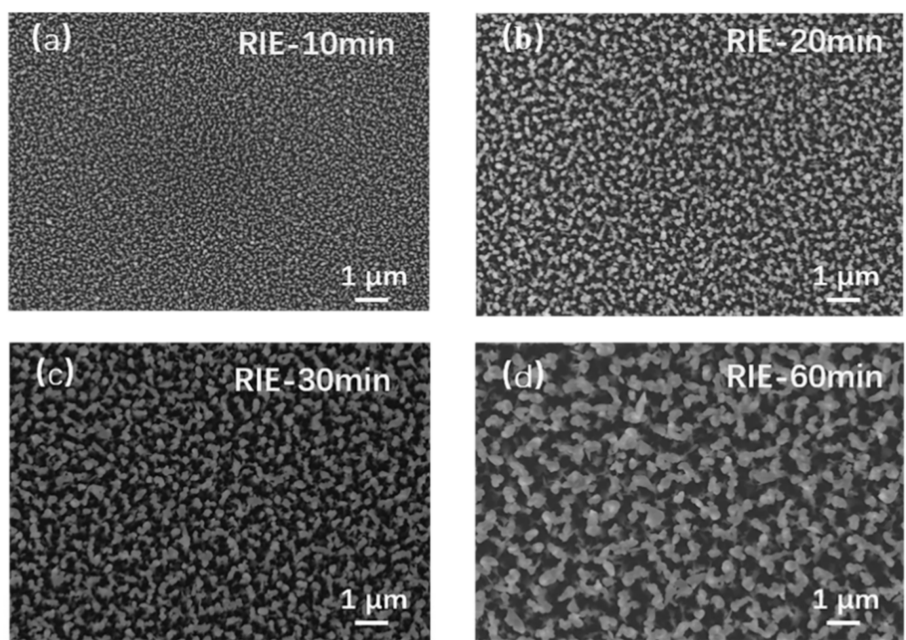

(e)
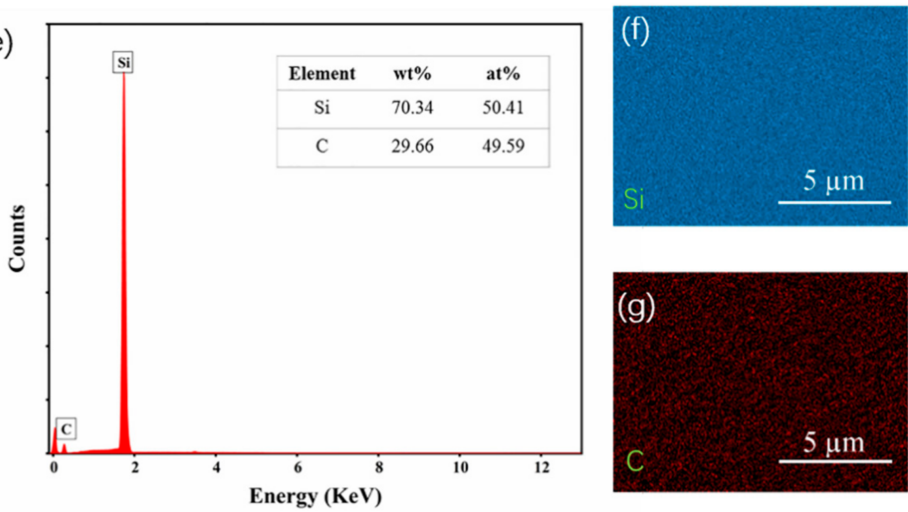

Figure 2. SEM images (plan view) of SiC nanoarrays prepared by RIE etching for (a) $10 \mathrm{~min}$, (b) $20 \mathrm{~min}$, (c) $30 \mathrm{~min}$, and (d) $60 \mathrm{~min}$, respectively (scale bar: $1 \mu \mathrm{m}$ ). (e) Energy-dispersive X-ray (EDX) spectrum of nanoarrays etched for $20 \mathrm{~min}$, the inset is the proportion of the chemical compositions. (f,g) EDX elemental mapping.

(a)

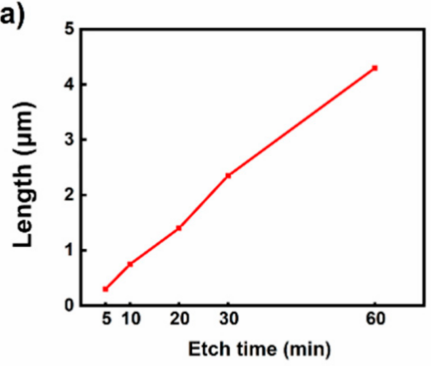

(c)

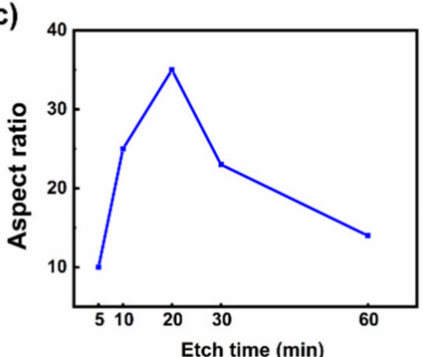

(b)

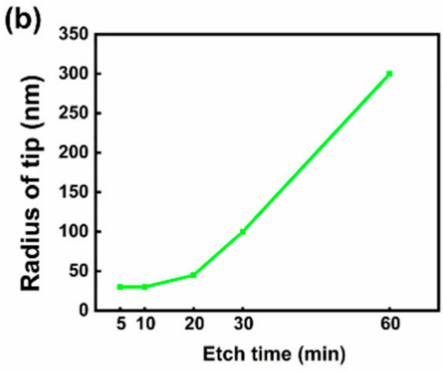

(d)

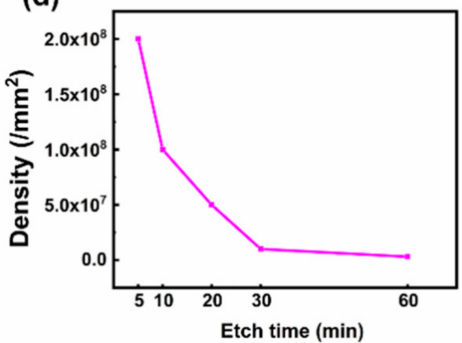

Figure 3. Plots of (a) length and (b) radius at the tip of a single nanocone under different etching times. (c) Plots of the aspect ratio of a single nanocone under different etching times. (d) Plots of density and etching time dependence. 
TEM samples were prepared by detaching the as-fabricated SiC nanoarrays from the remaining $\mathrm{SiC}$ wafer substrate by subjecting them to an ultrasonic treatment for $30 \mathrm{~min}$ in absolute ethanol. Figure 4a shows a typical TEM image of a single nanocone under low magnification. Individual $\mathrm{SiC}$ nanocones appear to have rough surfaces though retaining very sharp tips with a radius of curvature of approximately $30 \mathrm{~nm}$. Given the relatively low energy density associated with TEM sample preparation, we attribute this surface roughness not to the US treatment but to the RIE process. Figure $4 \mathrm{~b}$ shows a typical HR-TEM image recorded from the highlighted area in Figure 4a. Note the singlecrystalline nature of the as-synthesized nanostructure. Figure 4c shows the corresponding fast Fourier transformation (FFT), which we find is near identical over the entire measured cone, highlighting the crystallographic uniformity of the emitter. The measured $d$ spacing of $0.267 \mathrm{~nm}$ between two neighboring lattice fringes corresponds to the plane distance of crystalline $4 \mathrm{H}-\mathrm{SiC}$, [35] supporting our claims that the etching of the nanoarray is

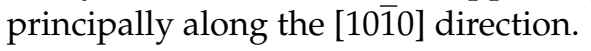

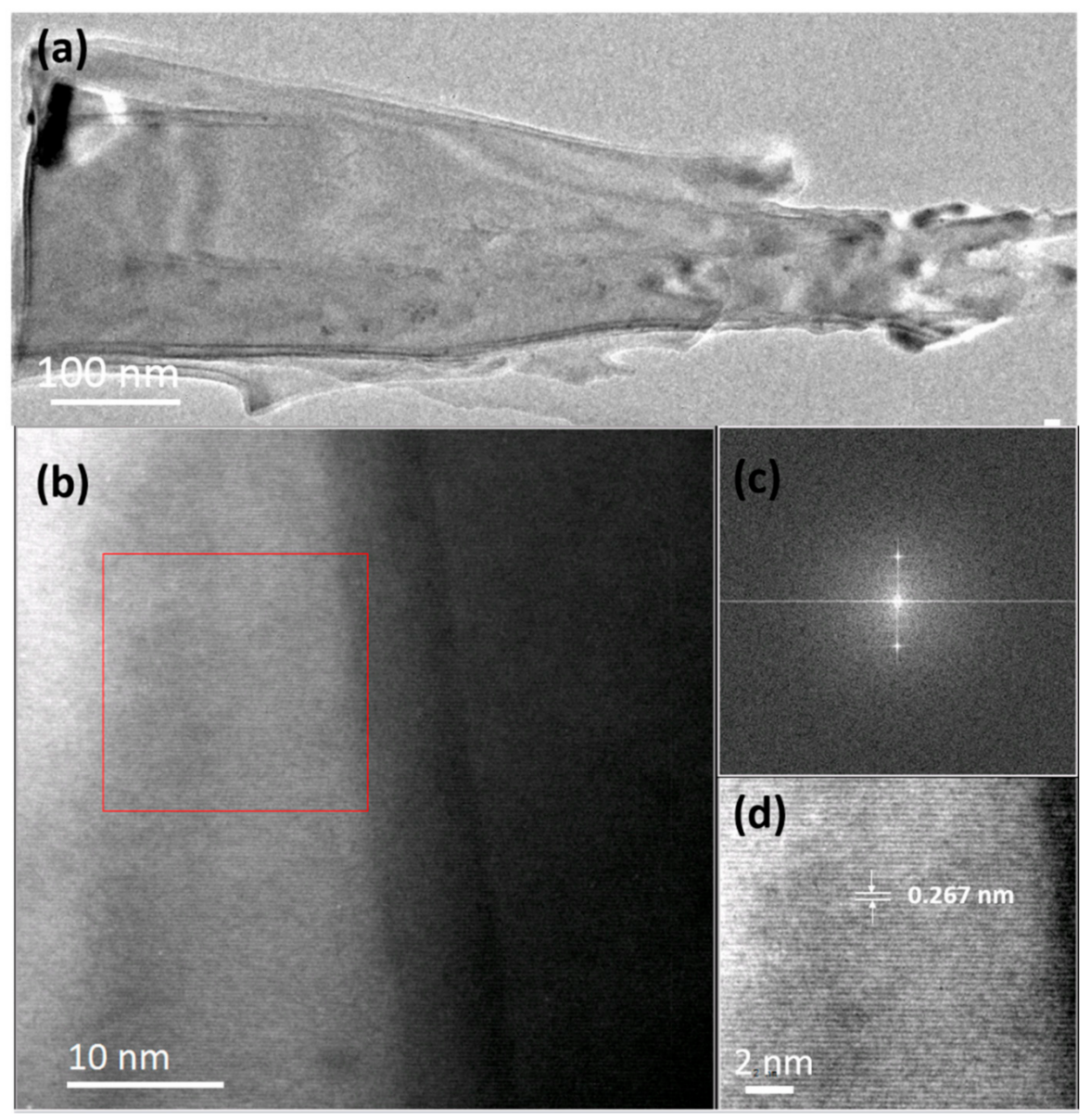

Figure 4. (a) Typical cross-sectional TEM imagery of a post-etched nanoarray. (b) HRTEM image (scale bar: $10 \mathrm{~nm}$ ) and (c) corresponding FFT (Image J) of the nanostructure within the cone-shaped $\mathrm{SiC}$ nanoarrays of a sample etching for $20 \mathrm{~min}$. (d) HRTEM image shows the lattice spacing in the red frame area of $(\mathbf{b})$. (Scale bar: $2 \mathrm{~nm}$ ).

The FE characteristics of the fabricated SiC nanoarrays were investigated. The current emission density $(\mathrm{J})$ as a function of applied electric field (E) is shown in Figure 5a. In order to study the effect of etching time on the FE performance, the J-E curves of different etching times (10 min, $20 \mathrm{~min}, 30 \mathrm{~min}$, and $60 \mathrm{~min}$ ) were measured. Figure $5 \mathrm{c}$ shows the extracted turn-on electric field (defined elsewhere [36]) $E_{\text {to }}$ with etching time. As the etching time increases, $E_{\text {to }}$ increases and $\mathrm{J}$ (under a constant field of $8 \mathrm{~V} / \mu \mathrm{m}$ ) tends to decrease. As the etch time increases, finer nanostructures, due to their energetically preferential 
geometry, tend to localize the etching plasma, and as a result, they are readily etched away, normalizing the surface, with the diameters of remaining nanostructures gradually become thicker, resulting in the lower field enhancement effect and fewer nanostructures available for effective electron emission. In the context of the FE measurements, we found an optimal etching time to be of the order of $20 \mathrm{~min}$.

(a)

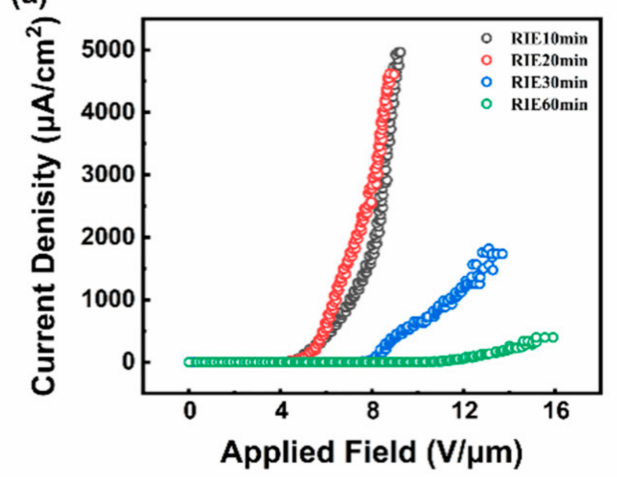

(c)

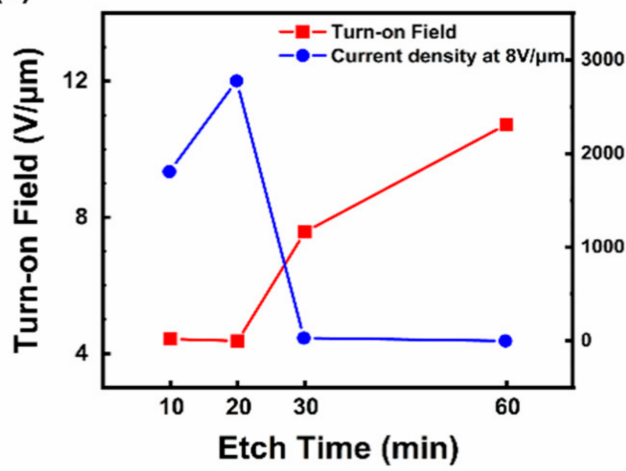

(b)

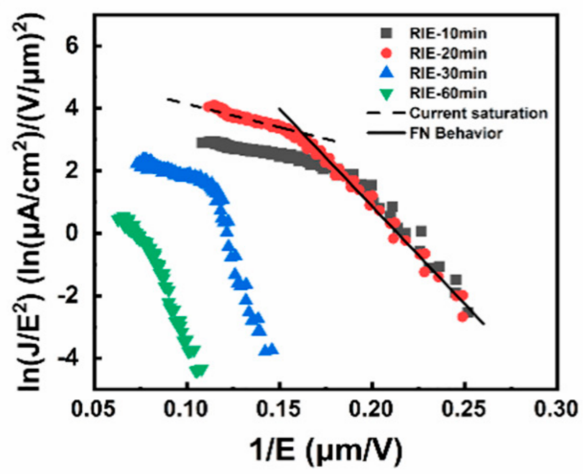

(d)

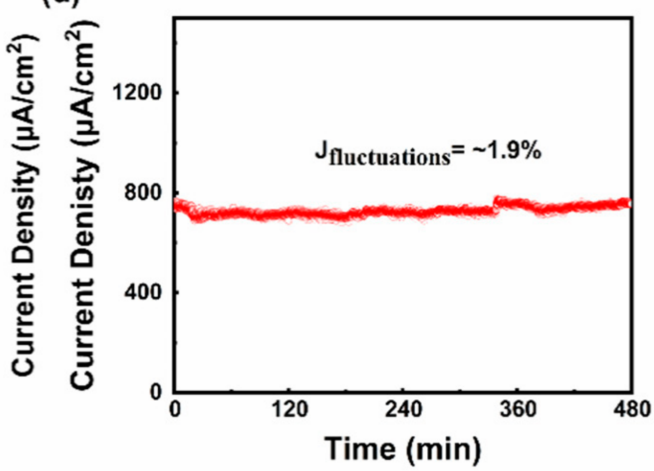

Figure 5. (a) Typical current density (J)- electric field (E) curve of the SiC nanoarrays fabricated as a function of etching time with the anode-cathode separation distance fixed at $300 \mu \mathrm{m}$. (b) The corresponding Fowler-Nordheim ( $\mathrm{F}-\mathrm{N})$ plots with different etching times. (c) The $\mathrm{E}_{\text {to }}$ and current density applied $8 \mathrm{~V} / \mu \mathrm{m}$ of nanoarrays in different etching times. (d) The current emission stabilities of $\mathrm{SiC}$ nanoarrays at an etching time of $20 \mathrm{~min}$ over $8 \mathrm{~h}$.

Although less extensive than the family of nanocarbons, there have been various theoretical and experimental research projects conducted on FE for a variety of semiconducting materials since the 1960s [37]. Generally, the FE of n-type high-resistance and p-type semiconductors shows non-linear Fowler-Nordheim (F-N) behavior [27,38-41]. Such J-E profiles can be broadly divided into three regions. As a function of increasing field strength, these include: (1) standard F-N or zero current approximation; (2) saturation region, in which emission is limited by an insufficient supply of carriers due to a p-n junction inverse bias; and (3) rapid increase in emission current as the field penetration becomes sufficient for impact ionization in the space-charge region allowing the carrier density to increase progressively [38]. Others have reported on the electron emission from SiC nanoarrays [41-43], noting F-N-like emission where [44],

$$
J=\left(\frac{A \beta^{2} E^{2}}{\Phi}\right) e^{-B \Phi^{\frac{3}{2}}(\beta E)^{-1}}
$$

Here J is current emission density, $\mathrm{E}$ is applied field, $\Phi$ is the work function of emitting material, $\mathrm{A}=1.54 \times 10^{-6} \mathrm{~A} \mathrm{eV} \mathrm{V}^{-2}, \mathrm{~B}=6.83 \times 10^{3} \mathrm{eV}^{-3 / 2} \mathrm{~V} \mathrm{\mu m}^{-1}$ and $\beta$ is the field enhancement factor. As a wide bandgap semiconductor $\left(E_{g}=3.23 \mathrm{eV}\right)$, the FE behavior of $\mathrm{SiC}$ is significantly different from that of metallic materials, which can be seen from 
the observed non-linear F-N characteristics (Figure 5b). These can be divided into F-N behavior and an approximate saturation region, which are respectively linearly fitted (Figure $5 b$ ). The slope of $\mathrm{F}-\mathrm{N}$ behavior plots can be represented by $\mathrm{k}=-6830 \Phi^{3 / 2} / \beta$, thereby allowing $\beta$ extraction. The $\mathrm{k}$-value depends on the linear slope of the $\mathrm{F}-\mathrm{N}$ plots and $\Phi$ value. Figure A3a shows UPS spectra, and the left/right panel of Figure A3b shows the secondary electron cut-off and the Fermi level regions, respectively. WF is determined from the secondary electron cut-off as $\Phi=h v-\left|E_{\text {cut-off }}-E_{F}\right|$, where $h v, E_{\text {cut-off }}$ and $E_{F}$ are the photon energy of excitation light (He I discharge lamp, $21.2 \mathrm{eV}$ ), the secondary electron cut-off energy, and Fermi level, respectively. The SiC WF was empirically found to be $4.2( \pm 0.1) \mathrm{eV}$. Based on this, the corresponding $\beta$-values were 1190 (10 min), 1260 (20 min), 418 (30 $\mathrm{min})$, and $483(60 \mathrm{~min})$. We noticed that the $\beta$-value of $30 \mathrm{~min}$ is slightly lower than that of $60 \mathrm{~min}$, which is attributed to the reduction of the electrostatic field screening effect caused by the decrease of the emitter density. Compared with bulk materials, due to the high aspect ratio of one-dimensional nanostructures, their FE properties are often significantly improved through the engineering of high aspect ratio one-dimensionality. However, large surface area, low mass, and low melting points make many such high aspect ratio nanostructures vulnerable to chemical and physical erosion and structural damage. Therefore, the stability of current emission is undoubtedly important and remains a challenge in the production of 1D nanomaterial field emitters.

The current emission stability of the as-fabricated field emitters is shown in Figure $5 \mathrm{~d}$, which shows the time-dependent emission current over $8 \mathrm{~h}$ (RIE-20 min). Measurements were acquired every second at $5 \times 10^{-6} \mathrm{~Pa}$ and an emission current of $730 \mu \mathrm{A}$. The $20 \mathrm{~min}$ RIE samples tended to show high emission stability. The emission stability, calculated by,

$$
\mathrm{J}_{\mathrm{i} \text {, fluctuation }}=\sqrt{\left(\mathrm{I}_{\mathrm{i}}-\overline{\mathrm{I}}\right)^{2}} / \overline{\mathrm{I}}
$$

where $\bar{I}$ is the average emission current and $I_{i}$ is the current at any moment, stayed within $1.9 \pm 1 \%$ of the average value of $\mathrm{J}_{\mathrm{i}}$, fluctuation across the entire measurement period. We attributed such excellent emission stability mainly to the known high physical and chemical stability of $\mathrm{SiC}$ and high dielectric breakdown field strength, high-temperature resistance, and thermal conductivity [2]. These results confirm that $\mathrm{SiC}$ nanoarrays etched by RIE could be an excellent candidate for high-power $[10,11]$ stable field emitters, and this preparation method performs a viable means of producing such field emitters.

\section{Conclusions}

Here we have successfully prepared $\mathrm{SiC}$ nanoarrays with a highly vertical orientation by adjusting the RIE etching parameters, providing a new low-cost approach for the preparation of nanostructured field emitters. The SiC nanoarrays are spatially dense $\left(\sim 10^{7} \mathrm{~mm}^{-2}\right)$, adopt conical morphologies, offer sharp tips $(\sim 30 \mathrm{~nm})$ and show high local field enhancement effects $(\beta=1260)$. The FE test results show that the turn-on field of the nanoarray is about $4.3 \mathrm{~V} / \mu \mathrm{m}$, indicating competitive FE performance. The long-term current emission stability shows that the $8 \mathrm{~h}$ fluctuation is only $1.9 \pm 1 \%$, which has high stability and is expected to be used in various applications such as traveling wave tubes and flat-panel displays.

Author Contributions: According to the journal proposed scheme, the authors have contributed in the following ways: Conceptualization: C.L.; Methodology: C.L. and J.X.; Software: J.Z. and K.C.; Validation: C.L., M.T.C. and Z.L.; Formal analysis: J.X. and X.L.; Investigation: J.X. and J.Z.; Resources: C.L., Z.L. and Q.D.; Data curation: J.X. and S.Z.; Writing—original draft preparation: J.X.; Writing-review and editing: C.L. and M.T.C.; Visualization: J.X. and G.L.; Supervision: C.L., Z.L. and Q.D.; Project administration: C.L., Z.L. and Q.D.; Funding acquisition: C.L. and Q.D. All authors have read and agreed to the published version of the manuscript. 
Funding: This research was funded by Strategic Priority Research Program of Chinese Academy of Sciences (Grant No. XDB36000000), the National Natural Science Foundation of China (Grant No. 51972072, 52072084, 51925203), CAS Interdisciplinary Innovation Team (grant no. JCTD-2018-03), the Key Area Research and Development Program of Guangdong Province (Grant no. 2020B0101020002) and the GBA National Institute for Nanotechnology Innovation (Grant no. 2020GN0106), the National Key R\&D Program of China (Grant No. 2016YFA0202000).

Data Availability Statement: The data presented in this study are available on request from the corresponding author.

Conflicts of Interest: The authors declare no conflict of interest. The funders had no role in the design of the study, in the collection, analyses, or interpretation of data, in the writing of the manuscript; or in the decision to publish the results.

\section{Appendix A}

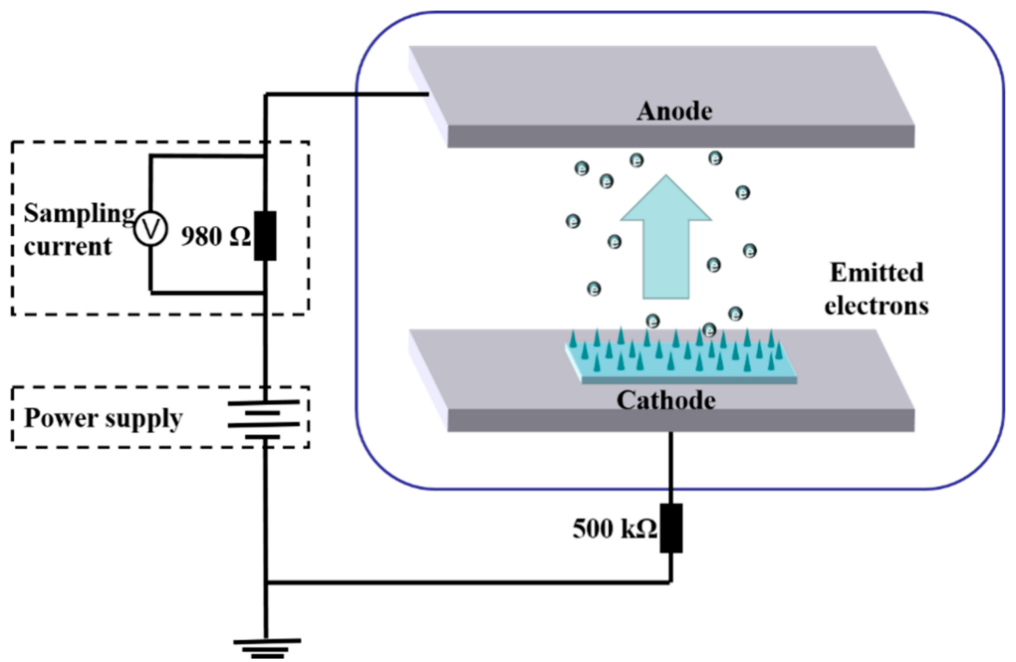

Figure A1. Schematic diagram of field-emission measurement.
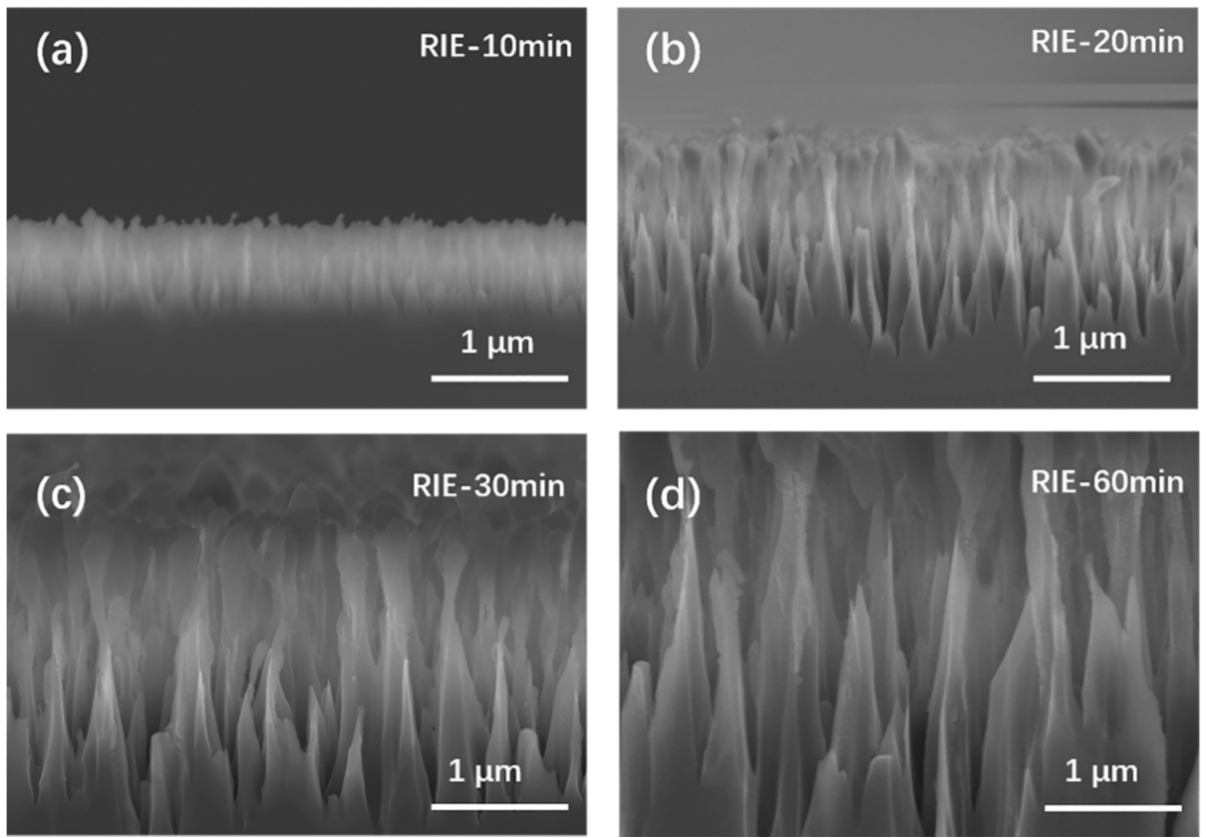

Figure A2. Cross-sectional SEM images of the silicon carbide nanoarray after RIE etching for (a) 10, (b) 20, (c) 30, and (d) $60 \mathrm{~min}$, respectively. Scale bar: $1 \mu \mathrm{m}$. 
(a)

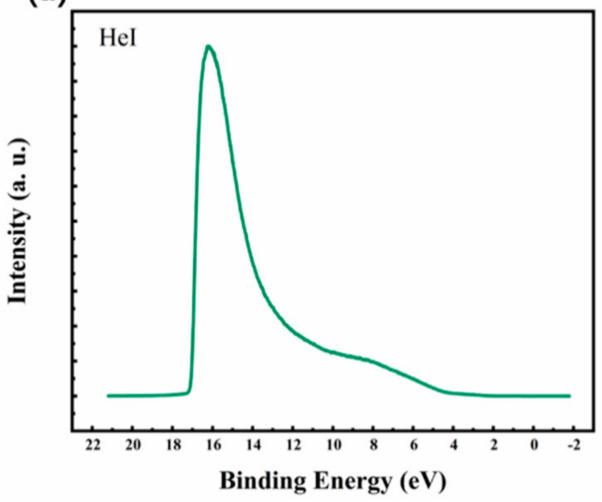

(b)

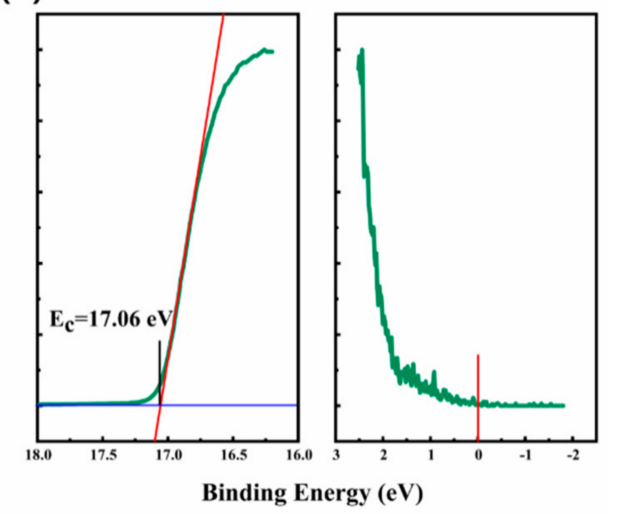

Figure A3. (a) Global spectrum of ultraviolet photoelectron spectroscopy. Left and right panel of (b) shows the secondary electron cut-off and the Fermi level regions, respectively, to determine the work function (WF).

\section{References}

1. Iijima, S. Helical Microtubules of Graphitic Carbon. Nature 1991, 354, 56-58. [CrossRef]

2. Casady, J.B.; Johnson, R.W. Status of silicon carbide ( $\mathrm{SiC})$ as a wide-bandgap semiconductor for high-temperature applications: A review. Solid-State Electron. 1996, 39, 1409-1422. [CrossRef]

3. Wong, E.W.; Sheehan, P.E.; Lieber, C.M. Nanobeam Mechanics: Elasticity, Strength, and Toughness of Nanorods and Nanotubes. Science 1997, 277, 1971-1975. [CrossRef]

4. Fan, J.Y.; Wu, X.L.; Chu, P.K. Low-dimensional SiC nanostructures: Fabrication, luminescence, and electrical properties. Prog. Mater. Sci. 2006, 51, 983-1031. [CrossRef]

5. Chen, S.L.; Li, W.J.; Li, X.X.; Yang, W.Y. One-dimensional SiC nanostructures: Designed growth, properties, and applications Prog. Mater. Sci. 2019, 104, 138-214. [CrossRef]

6. Yang, Y.; Meng, G.; Liu, X.; Zhang, L.; Hu, Z.; He, C.; Hu, Y. Aligned SiC Porous Nanowire Arrays with Excellent Field Emission Properties Converted from Si Nanowires on Silicon Wafer. J. Phys. Chem. C 2008, 112, 20126-20130. [CrossRef]

7. Wei, G.D.; Qin, W.P.; Kim, R.J.; Sun, J.B.; Zhu, P.F.; Wang, G.F.; Wang, L.L.; Zhang, D.S.; Zheng, K.Z. Quantum confinement effect and field emission characteristics of ultrathin 3C-SiC nanobelts. Chem. Phys. Lett. 2008, 461, 242-245. [CrossRef]

8. Chen, C.M.; Chen, S.L.; Shang, M.H.; Gao, F.M.; Yang, Z.B.; Liu, Q.; He, Z.Y.; Yang, W.Y. Fabrication of highly oriented 4H-SiC gourd-shaped nanowire arrays and their field emission properties. J. Mater. Chem. C 2016, 4, 5195-5201. [CrossRef]

9. Wang, L.; Jiang, L.; Zhang, T.; Gao, F.M.; Chen, S.L.; Yang, W.Y. Graphene/SiC heterojunction nanoarrays: Toward field emission applications with low turn-on fields and high stabilities. J. Mater. Chem. C 2019, 7, 13748-13753. [CrossRef]

10. Doğan, S.; Teke, A.; Huang, D.; Morkoç, H.; Roberts, C.B.; Parish, J.; Ganguly, B.; Smith, M.; Myers, R.E.; Saddow, S.E. 4H-SiC photoconductive switching devices for use in high-power applications. Appl. Phys. Lett. 2003, 82, 3107-3109. [CrossRef]

11. Chen, Z.; Bai, S.; Li, G.; Li, X.; Wan, H. Intense electron emission of SiC nanowires cathode used in high power microwave. High Power Laser Part. Beams 2010, 22, 2945-2948. [CrossRef]

12. Matsunami, H. Current SiC Technology for Power Electronic Devices Beyond Si. Microelectron. Eng. Microelectron. Eng. 2006, 83, 2-4. [CrossRef]

13. Wu, R.B.; Zhou, K.; Wei, J.; Huang, Y.Z.; Su, F.; Chen, J.J.; Wang, L.Y. Growth of Tapered SiC Nanowires on Flexible Carbon Fabric: Toward Field Emission Applications. J. Phys. Chem. C 2012, 116, 12940-12945. [CrossRef]

14. Zhou, X.T.; Lai, H.L.; Peng, H.Y.; Au, F.C.K.; Liao, L.S.; Wang, N.; Bello, I.; Lee, C.S.; Lee, S.T. Thin $\beta$-SiC nanorods and their field emission properties. Chem. Phys. Lett. 2000, 318, 58-62. [CrossRef]

15. Tang, S.; Tang, J.; Uzuhashi, J.; Ohkubo, T.; Hayami, W.; Yuan, J.S.; Takeguchi, M.; Mitome, M.; Qin, L.C. A stable LaB6 nanoneedle field-emission point electron source. Nanoscale Adv. 2021, 3, 2787-2792. [CrossRef]

16. Wu, R.; Zhou, K.; Yue, C.Y.; Wei, J.; Pan, Y. Recent progress in synthesis, properties and potential applications of SiC nanomaterials. Prog. Mater. Sci. 2015, 72, 1-60. [CrossRef]

17. van Zuuk, A.; Heerkens, C.T.H.; van Veen, A.H.V.; Teepen, T.F.; Wieland, M.J.; Groening, O.; Kruit, P. Fabrication and characterization of silicon carbide field-emitter array. Microelectron. Eng. 2004, 73-74, 106-110. [CrossRef]

18. Chen, S.L.; Ying, P.Z.; Wang, L.; Wei, G.D.; Gao, F.M.; Zheng, J.J.; Shang, M.H.; Yang, Z.B.; Yang, W.Y.; Wu, T. Highly flexible and robust N-doped SiC nanoneedle field emitters. Npg Asia Mater. 2015, 7, e157. [CrossRef]

19. Shen, G.; Bando, Y.; Golberg, D. Self-Assembled Hierarchical Single-Crystalline $\beta$-SiC Nanoarchitectures. Cryst. Growth Des. 2007, 7, 35-38. [CrossRef]

20. Kang, M.G.; Lezec, H.J.; Sharifi, F. Stable field emission from nanoporous silicon carbide. Nanotechnology $2013,24,065201$. [CrossRef] 
21. Oehrlein, G.S.; Tromp, R.M.; Tsang, J.C.; Lee, Y.H.; Petrillo, E.J. Near-Surface Damage and Contamination after $\mathrm{CF}_{4} / \mathrm{H}_{2}$ Reactive Ion Etching of Si. J. Electrochem. Soc. 1985, 132, 1441. [CrossRef]

22. Sugiura, J.; Lu, W.J.; Cadien, K.C.; Steckl, A.J. Reactive Ion Etching of SiC Thin-Films Using Fluorinated Gases. J. Vac. Sci. Technol. B 1986, 4, 349-354. [CrossRef]

23. Chabert, P.; Cunge, G.; Booth, J.P.; Perrin, J. Reactive ion etching of $\mathrm{SiC}$ in SF6 gas: Detection of CF, $\mathrm{CF}_{2}$ and $\mathrm{SiF}_{2}$ etch products. Appl. Phys. Lett. 2001, 79, 916-918.

24. Kawahara, K.; Krieger, M.; Suda, J.; Kimoto, T. Deep levels induced by reactive ion etching in n- and p-type 4H-SiC. J. Appl. Phys. 2010, 108, 023706. [CrossRef]

25. Hamelin, B.; Yang, J.; Ayazi, F. Precision Deep Reactive Ion Etching of Monocrystalline 4H-SiCOI for Bulk Acoustic Wave Resonators with Ultra-Low Dissipation. J. Electrochem. Soc. 2021, 168, 017512. [CrossRef]

26. Gupta, A.P.; Park, S.; Yeo, S.J.; Jung, J.; Cho, C.; Paik, S.H.; Park, H.; Cho, Y.C.; Kim, S.H.; Shin, J.H.; et al. Direct Synthesis of Carbon Nanotube Field Emitters on Metal Substrate for Open-Type X-ray Source in Medical Imaging. Materials 2017, 10, 878. [CrossRef]

27. Choueib, M.; Martel, R.; Cojocaru, C.S.; Ayari, A.; Vincent, P.; Purcell, S.T. Current saturation in field emission from H-passivated Si nanowires. ACS Nano 2012, 6, 7463-7471. [CrossRef]

28. Chu, F.H.; Huang, C.W.; Hsin, C.L.; Wang, C.W.; Yu, S.Y.; Yeh, P.H.; Wu, W.W. Well-aligned ZnO nanowires with excellent field emission and photocatalytic properties. Nanoscale 2012, 4, 1471-1475. [CrossRef]

29. Wang, Z.L.; Wang, Q.; Li, H.J.; Li, J.J.; Xu, P.; Luo, Q.; Jin, A.Z.; Yang, H.F.; Gu, C.Z. The field emission properties of high aspect ratio diamond nanocone arrays fabricated by focused ion beam milling. Sci. Technol. Adv. Mater. 2005, 6, 799-803. [CrossRef]

30. Zhang, J.; Xu, J.; Ji, D.X.; Xu, H.; Sun, M.; Wu, L.; Li, X.Y.; Wang, Q.L.; Zhang, X.B. Development of an electron gun based on CNT-cathode for traveling wave tube application. Vacuum 2021, 186, 110029. [CrossRef]

31. Park, S.; Gupta, A.P.; Yeo, S.J.; Jung, J.; Paik, S.H.; Mativenga, M.; Kim, S.H.; Shin, J.H.; Ahn, J.S.; Ryu, J. Carbon Nanotube Field Emitters Synthesized on Metal Alloy Substrate by PECVD for Customized Compact Field Emission Devices to Be Used in X-Ray Source Applications. Nanomaterials 2018, 8, 378. [CrossRef]

32. Gupta, A.P.; Yeo, S.J.; Mativenga, M.; Jung, J.; Kim, W.; Lim, J.; Park, J.; Ahn, J.S.; Kim, S.H.; Chae, M.S.; et al. A feasibility study of a portable intraoperative specimen imaging X-ray system based on carbon nanotube field emitters. Int. J. Imaging Syst. Technol. 2021, 31, 1128-1135. [CrossRef]

33. Han, S.Y.; Kim, K.H.; Kim, J.K.; Jang, H.W.; Lee, K.H.; Kim, N.; Kim, E.D.; Lee, J. Ohmic contact formation mechanism of Ni on n-type 4H-SiC. Appl. Phys. Lett. 2001, 79, 1816-1818. [CrossRef]

34. Liu, Y.H.; Sun, Y.J.; Zhao, G.J.; Liao, L.M.; Wang, T.; Chen, Z.Z. Crystal structure induced residue formation on $4 \mathrm{H}-\mathrm{SiC}$ by reactive ion etching. Aip Adv. 2016, 6, 065219. [CrossRef]

35. Wang, Y.X.; Wen, J.; Guo, Z.; Tang, Y.Q.; Tang, H.G.; Wu, J.X. The preparation of single-crystal $4 \mathrm{H}-\mathrm{SiC}$ film by pulsed XeCl laser deposition. Thin Solid Film. 1999, 338, 93-99. [CrossRef]

36. Cole, M.T.; Parmee, R.J.; Kumar, A.; Collins, C.M.; Kang, M.H.; Xiao, J.; Cepek, C.; Yuan, X.; Milne, W.I. Conjugated polyelectrolyte nano field emission adlayers. Nanoscale Horiz. 2016, 1, 304-312. [CrossRef]

37. Choueib, M.; Ayari, A.; Vincent, P.; Bechelany, M.; Cornu, D.; Purcell, S.T. Strong deviations from Fowler-Nordheim behavior for field emission from individual $\mathrm{SiC}$ nanowires due to restricted bulk carrier generation. Phys. Rev. B 2009, 79, 075421. [CrossRef]

38. Baskin, L.M.; Lvov, O.I.; Fursey, G.N. General features of field emission from semiconductors. Phys. Status Solidi 2010, 47, 49-62. [CrossRef]

39. Liu, K.X.; Chiang, C.J.; Heritage, J.P. Photoresponse of gated p-silicon field emitter array and correlation with theoretical models. J. Appl. Phys. 2006, 99, 034502. [CrossRef]

40. John, R.A., Jr. Photosensitive Field Emission from p-Type Germanium. J. Appl. Phys. 1965, 36, 3221-3227. [CrossRef]

41. Carapezzi, S.; Castaldini, A.; Fabbri, F.; Rossi, F.; Negri, M.; Salviati, G.; Cavallini, A. Cold field electron emission of large-area arrays of SiC nanowires: Photo-enhancement and saturation effects. J. Mater. Chem. C 2016, 4, 8226-8234. [CrossRef]

42. Ryu, Y.; Tak, Y.; Yong, K. Direct growth of core-shell SiC-SiO2nanowires and field emission characteristics. Nanotechnology 2005, 16, S370-S374. [CrossRef]

43. Pan, Z.W.; Lai, H.L.; Au, F.C.K.; Duan, X.F.; Zhou, W.Y.; Shi, W.S.; Wang, N.; Lee, C.S.; Wong, N.B.; Lee, S.T.; et al. Oriented silicon carbide nanowires: Synthesis and field emission properties. Adv. Mater. 2000, 12, 1186-1190. [CrossRef]

44. Fowler, R.H.; Nordheim, L. Electron emission in intense electric fields. Proc. R. Soc. Lond. Ser. A-Contain. Pap. Math. Phys. Character 1928, 119, 173-181. [CrossRef] 